\title{
O campo na dialética da geografia
}

Jean Tricart

Universidade Louis Pasteur de Estrasburgo - FR

p. $305-314$

\section{revista}

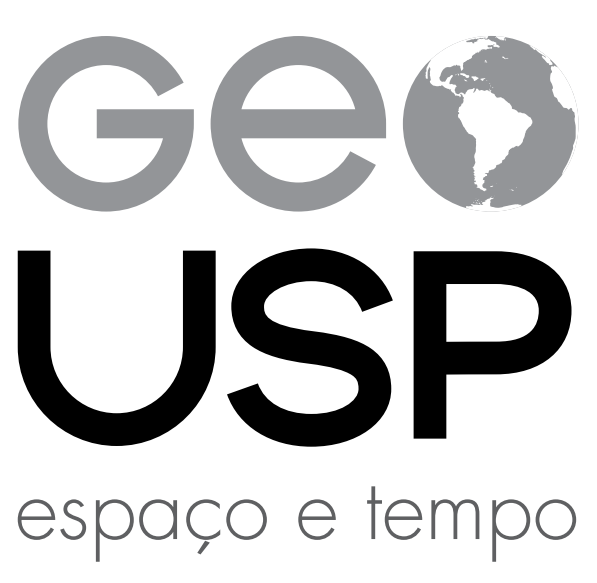

Volume $21 \cdot n^{\circ} 1(2017)$

ISSN 2179-0892
Como citar este artigo:

TRICART, J. O campo na dialética da geografia. Geousp Espaço e Tempo (Online), v. 21, n. 1, p. 305-314, abr. 2017. ISSN 2179-0892.

Disponível em: < http://www.revistas.usp.br/geousp/ article/view/125762 > . doi: 10.11606/issn.2179-0892. geousp.2017.125762.

\section{(c) $(1)(9$}

Este artigo está licenciado sob a Creative Commons Attribution 4.0 License. 


\section{O campo na dialética da geografia ${ }^{1}$}

\section{Jean Tricart}

Uma decisão recente de nossa UER ${ }^{2}$ (Universidade Louis Pasteur) resolveu manter, para 1977, as verbas afetas às "excursões" no orçamento anterior, enquanto a soma total das verbas que nos atribuem diminui, pois é preciso defender o franco... Na realidade, a manutenção dos fundos nominais enquanto todos os preços aumentam significa uma diminuição do poder de compra. Todavia, nossa decisão manifesta uma orientação metodológica, a afirmação de uma política científica e pedagógica: a miséria em meio à qual procuramos trabalhar, seja como for, assume graus diversos, e nós queremos que o trabalho de campo sofra menos do que outras atividades. Trata-se, portanto, de uma escolha. Será que ela se justifica? De que maneira?

Antes de tudo, devemos justificar o lugar que o campo ocupa no desenvolvimento do conhecimento, o que nos leva a definir uma posição metodológica. Por sua vez essa posição metodológica, uma vez definida, implica uma determinada concepção do trabalho de campo que possa associar-se a ela numa dialética. Mais ainda: disso tudo decorre uma orientação pedagógica destinada a permitir aos jovens a aquisição do manejo dessa dialética nas melhores condições possíveis.

\section{O campo na metodologia geográfica}

Coloquemos, de passagem, nossa opinião: para nós não existem métodos próprios da geografia, mas métodos de aplicação mais geral cujo uso pela geografia é só um caso entre outros. Esses métodos do conhecimento associam-se a conceitos que se inserem numa taxonomia cujos níveis mais altos estão reservados a um amplo grupo de disciplinas, e só os níveis inferiores, subordinados, são específicos de uma disciplina ou de um ramo de disciplina. Para nós, uma disciplina define-se por seu objeto, que é um elemento do conhecimento. Se se considera que todos os fenômenos que constituem nosso universo são interdependentes, nenhuma disciplina tem um objeto realmente específico. A análise de fenômenos particulares, tal como é encarada pelas diversas disciplinas, não deve conduzir ao isolamento desses fenômenos. Uma atitude dialética deve permitir a recolocação dos resultados analíticos obtidos em seu contexto de interferências. Em síntese, nossa abordagem é decididamente sistêmica, já que a nosso ver a teoria dos sistemas é o melhor instrumento lógico de que dispomos atualmente. Ela engloba e supera a "dialética da natureza" esboçada há um século por Engels.

1 Título original: "Le Terrain dans la Dialectique de la Géographie", publicado em Heródote, n. 8, p. 105-120, oct./déc. 1977. Trad. Lylian Coltrinari.

2 UER: unidade de ensino e pesquisa. 
É evidente que a posição da geografia no tríplice ponto de encontro das ciências do homem, da vida e da matéria (Y. Lacoste), de acordo com nossa tese, dificulta a explanação dessa tese, fazendo surgir o perigo de generalizações inadequadas. Portanto, vamos nos limitar inicialmente a certos aspectos do estudo do meio natural.

método analítico recorreu com bastante frequência à experimentação para o estudo dos fenômenos naturais. Isto é feito, em grande parte, segundo uma abordagem empírica. Como resultado registra-se um certo atraso na conceituação, inseparável de um certo "flou" metodológico. Preocupado há tempos com a epistemologia, consegui estabelecer as seguintes distinções:

(a) a simulação consiste na reprodução de um fenômeno natural após isolá-lo de seu contexto, de maneira a melhor conhecer parte dos parâmetros que o comandam. Dessa maneira, é possível, por um lado, introduzir à vontade variações nesses parâmetros e, por outro, realizar medições com toda comodidade. Chega-se assim a correlações que se exprimem, na lógica cartesiana, sob a forma de relações de causa e efeito e, na abordagem sistêmica, em termos de entradas e saídas. A simulação se aplica fundamentalmente aos fenômenos da matéria. A experimentação dos físicos e dos químicos é uma forma de simulação, embora sob um nome diferente, criador de confusão.

No estudo da natureza, a simulação assume formas diferentes, das quais apresentamos alguns exemplos:

- as experiências em laboratório sobre o comportamento das rochas face às alternâncias gelo-degelo, da cristalização do sal, da percolação de soluções diversas, destinadas a precisar os parâmetros dos mecanismos de meteorização;

- a simulação de chuvas mediante dispositivos de aspersão para estudo da degradação do solo sob o efeito do impacto das gotas de chuva (erosão pluvial) e do escoamento resultante;

- os modelos reduzidos de trechos de cursos de água, para estudo dos processos de elaboração dos leitos fluviais e dos fluxos detríticos. Existem hoje três categorias de modelos: os modelos físicos (modelos reduzidos), cuja configuração corresponde àquela que conhecemos na natureza; os modelos analógicos, constituídos, por exemplo, por resistências e circuitos nos quais se faz passar uma corrente elétrica e que se comportam da mesma maneira que o objeto natural representado; e os modelos matemáticos, constituídos por baterias de equações e que correspondem a uma formalização do fenômeno natural.

(b) a experimentação propriamente dita, que não está separada da simulação por qualquer limite nítido, o que fica evidente no vocabulário. Com efeito, ela consiste também, dentro de certos limites, em fazer variar certos parâmetros de maneira controlada. Existe todavia uma diferença prática: o objetivo da experimentação é, em principio, controlar os efeitos esperados de tal ou qual modificação introduzida nas condições iniciais existentes na natureza. 
Por exemplo: depois de um período consagrado ao estudo dos fenômenos espontâneos em uma pequena bacia-vertente, são introduzidas modificações sob a forma de manejo (edificação de banquetas, cultura em faixas alternadas, implantação de cortinas de árvores etc.) e medem seus efeitos. Chama-se a isto "bacia experimental".

Os agrônomos praticam a experimentação há muito tempo, por um lado para estabelecer as modificações de rendimento que decorrem das melhorias genéticas das plantas e de outro para determinar os efeitos de práticas novas, tais como aquelas citadas quando nos referimos à bacia experimental.

Há bastante tempo que uma tecnologia normalizada vem sendo aprimorada nas estações agronômicas. Ela se baseia na escolha de baterias de parcelas localizadas em princípio em condições análogas, às quais se aplicam simultaneamente tratamentos diferentes. A seguir recorre-se a técnicas estatísticas para estabelecer correlações. Esse procedimento permite ter os mesmos parâmetros climáticos em todas as parcelas, estreitamente agrupadas num espaço reduzido. Temos agito da mesma maneira em pequenas bacias experimentais, ao escolher duas bacias tão parecidas quanto possível, deixando uma delas, por exemplo, com a vegetação original, enquanto a outra é submetida a reflorestamento de coníferas. Assim, puderam se comparar a interceptação e o escoamento no Maciço Xistoso Renano, sob caducifólias e sob coníferas.

Os modelos físicos, analógicos e matemáticos servem, antes de tudo, à experimentação: por exemplo, para determinar os possíveis efeitos na modificação do regime de um curso de água por obras de retenção ou captação de águas, ou ainda de manejo do leito (soleiras, espigões, diques etc.). $O$ alto custo dos modelos físicos faz com que eles não sejam construídos e explorados senão de maneira excepcional para o desenvolvimento de nossos conhecimentos fundamentais. Neles repousam, entretanto, os brilhantes resultados obtidos pela escola de Uppsala (Suécia), fundada por F. Hjulström, em matéria de dinâmica fluvial.

Esses procedimentos não podem se aplicar às ciências da vida e do homem. A experimentação biológica existe, mas será necessário lembrar a oposição que suscita no plano ético? A experimentação social, mesmo aquela conduzida em campos de concentração, não pode ser considerada demonstrativa. Só resta a possibilidade de aplicar os modelos matemáticos: a "nova geografia" fez deles um de seus objetivos.

Mas esses procedimentos de simulação e de experimentação repousam necessariamente num confronto com a natureza. É ela que permite avaliar o grau de representatividade da simulação ou da área experimental. Simular uma chuva no laboratório é delicado e torna-se necessário criar dispositivos para obter gotas de água chegando ao solo com a mesma energia cinética que aquela das chuvas ao ar livre em tal ou qual região. O respeito à lei das semelhanças impõe pesadas limitações aos modelos reduzidos, tornando impossível, por exemplo, o estudo da competência. Para transpor os resultados da experimentação agronômica ao plano regional, é necessário dispor de cartas que mostrem a extensão do meio ambiente representado por cada parcela.

Voltamos assim a encontrar a necessidade de uma dialética campo-experimentação. 
Ela se manifesta a partir do momento em que se encara uma simulação. No caso das chuvas, é necessário conhecer a energia cinética transmitida pela chuva natural à superfície do solo, que é função da intensidade e a duração combinadas desta chuva. Porém, os registros pluviométricos normalizados não oferecem esses dados. É necessário suprir essa carência com medidas diretas na natureza: só assim as chuvas poderão ser simuladas de maneira satisfatória, e a medida de seus efeitos permitirão previsões. Mais ainda: só assim as chuvas simuladas serão úteis para testar as precauções a serem tomadas para assegurar a conservação de terras e das águas ao se pôr em prática um certo tipo de cultura, ou ao se desmatar tal ou qual vertente ou solo. Esse caminhar é indispensável para dar à pesquisa uma utilidade social.

$\bigcirc$ modelismo apresenta as mesmas exigências. $\bigcirc$ estabelecimento de um modelo físico requer a determinação de numerosos parâmetros por observação e medida no campo. A observação direta permitirá fazer do modelo uma imagem suficientemente semelhanteà natureza, portanto, com representatividade suficiente. Énecessáriotambém conhecer o funcionamento dos fenômenos naturais para reproduzi-los no modelo. Isto não se consegue de improviso. É necessário fazer ajustes sucessivos que traduzam uma abordagem dialética, e a seguir é preciso dedicar-se a ensaios que reproduzam esta ou aquela situação observável na natureza, permitindo assim o controle do funcionamento do modelo. $\bigcirc$ mesmo se pode dizer dos modelos matemáticos, os únicos utilizáveis em Geografia Humana. Seja como for, todo modelo é uma simplificação do objeto que pretende representar. Esta simplificação é mais ou menos aproximada; na melhor das hipóteses, ela é aceitável dentro de certos limites. Os limites de validade dos modelos físicos foram estudados, o que não acontece com os outros modelos. Só o confronto com a realidade natural permite definir esses limites de validade, e a partir dele o uso que se pode fazer do modelo. Voltamos a encontrar a mesma dialética mencionada no caso da experimentação, e da qual um dos polos é o reconhecimento de campo.

Essa dialética assinala certos objetos ao conhecimento do campo. Vejamos quais.

\section{Exigências dialéticas do trabalho de campo}

$\mathrm{Na}$ dialética geral do conhecimento, temos inicialmente certo número de observações, de dados concretos fornecidos pela vida cotidiana. São eles o ponto de partida de raciocínios, de deduções que orientam a ação. São, na realidade, correlações. Esse comportamento lógico não é privilégio do homem: é o que permite aos animais subsistirem, de maneira mais ou menos trabalhosa ou elaborada. A diferença não é de natureza, mas de grau. Muitos animais são superiores a nós no domínio do registro dos dados: um cachorro tem vinte vezes mais células olfativas que nós e pode reunir, a partir de odores, uma massa de informação que somos incapazes de atingir e que comandam seu comportamento. Mas nós inventamos toda uma série de instrumentos que ampliam o campo de nossa percepção bem além de nossos sentidos, coisa que os animais não podem fazer, e aqui me permito evocar, sem mais, os diversos aparelhos de sensoriamento remoto (radar, infravermelho, diversos canais multiespectrais etc.) 
Também dispomos de "plataformas" de observação artificiais: aviões, satélites etc. Nosso campo de observação alargou-se imensamente. E mais: também dispomos, para nossas deduções, de meios técnicos consideráveis, como os computadores. O potencial de percepção e de tratamento da informação que podemos utilizar é enorme, e cresce cada vez mais. Por outro lado, nossa organização social incentiva esse comportamento ao evitar que se questione a utilização desses instrumentos. Para as tecnoestruturas e seus agentes políticos, o essencial é assegurar a venda desses equipamentos para que os fabricantes possam ter lucros. O CNRS pressiona seus laboratórios para que reservem parte das verbas à compra de grandes equipamentos, enquanto lhes recusa o pessoal técnico que os faria funcionar e não concede o dinheiro indispensável para continuar as pesquisas já começadas.

Impõe-se, pois, uma estratégia de pesquisa: a superabundância de informação acessível e disponível (lembro aqui os registros dos satélites, as coberturas de fotografias aéreas) obriga a fazer uma escolha, a selecionar certos tipos de informações que serão tratadas de acordo com as regras da arte.

Quais são as modalidades dessa escolha?

Deparamo-nos novamente com uma dialética que pode ser sintetizada da seguinte maneira: por um lado, precisamos de uma massa crítica de informações para elaborar um esquema lógico, esboçar correlações que perfaçam certa rede de interações e, do outro, enquanto elaboramos esse esquema, somos barrados por lacunas em nosso conhecimento. Faltam-nos certas informações, ignoramos certas interações que são necessárias precisar. Esse esquema, conceitualização ou modelização passa a ser um guia de observação, manda-nos de volta ao campo. Assim como o modelo físico, o esquema descansa sobre um certo número de dados de campo e, a seguir, uma vez estabelecido, exige o regresso ao campo para ser ajustado e "instruído", isto é, capaz de reproduzir corretamente os fenômenos a serem estudados.

A vantagem da abordagem sistêmica é dupla: ela nos permite realizar com facilidade esta oscilação dialética sem contestações radicais, autorizando-nos a passar do conhecimento qualitativo ao quantitativo ao preço de somente alguns ajustes. As interações que ela põe em evidência permitem apreciar as possibilidades de inserção de observações e de medidas precisas, assim como determinar o significado dessas medidas: esses dois pontos são fundamentais para quantificação. Com efeito, existem, por um lado, grandes riscos de interferência entre o fenômeno e sua própria medida (os físicos nos ensinaram isso há muito tempo) e, por outro, é difícil conseguir medir exatamente, tanto na natureza quanto nas sociedades humanas, o que nos interessa. Amiúde medimos indiretamente, de maneira convencional, mais ou menos adequada. Em questões de socioeconomia, o parâmetro político intervém nesse nível: falseando o termômetro, espera-se impedir que o doente tenha febre... Será necessário lembrar os índices comumente utilizados, como o PNB ou o índice dos preços?

Impõe-se, portanto, a segunda pergunta: qual é a maneira de proceder para melhorar a objetividade dos dados em que se fundamentam nossos raciocínios? 
Os problemas são um pouco diferente para a Geografia Física e a Geografia Humana, por razões políticas. Não há, porém, nenhuma oposição fundamental: existe simplesmente uma diferença de conjuntura, provavelmente muito provisória. Desde há muito, os organismos do Estado estabelecem estatísticas nos domínios da demografia, das atividades profissionais, da produção e comércio de bens, dos salários e dos preços, ou seja, todas as categorias de informações indispensáveis às pesquisas socioeconômicas da Geografia Humana, tanto regional quanto geral.

Aparentemente, o trabalho dos economistas, sociólogos e geógrafos parece facilitado. Eles não têm necessidade, como o geógrafo físico, de estabelecer eles mesmos, com meios parcimoniosamente medidos e sempre insuficientes, os dados de que precisam. Dessa maneira, eles podem, de imediato, explorar esse tesouro e lançarse ao tratamento dos dados que encontram nas estatísticas. A cartografia automática, simples transformação das tabelas estatísticas em cartogramas, muito lhes deve. Todavia, ao fazer isto os especialistas devem se colocar o problema político: esse tesouro é um tesouro de guerra, que não foi reunido por eles. Se deixarem os outros apalpá-lo, não é só por pura bondade... Se os tecnocratas não se questionam eles justificam de fato o procedimento adotado para o estabelecimento desses dados: encontramos novamente $\mathrm{O}$ problema da febre e do termômetro. Por exemplo: quanto maior o número de acidentes fatais de automóvel ou de incêndios de fábricas ou de marés negras, mais aumenta o PNB. Singular instrumento da felicidade dos súditos do reino!

Para escapar a esse círculo vicioso há uma solução: o espírito crítico e a indiscrição, sob a forma de trabalho de campo, isto é, inquéritos e observações pessoais. Mas mesmo nesse nível de abordagem coloca-se o problema da escolha, já que o indivíduo ou a pequena equipe que não dispõe do apoio das tecnoestruturas só pode abranger um campo limitado. Torna necessário escolher corretamente - um problema de tática, de acordo com o vocabulário de Y. Lacoste. As situações críticas, explosivas, são frequentemente favoráveis, assim como o estudo da propagação das epidemias o é para a medicina.

Poder-se-ia pensar que o estudo da natureza não conhece esta situação. Não partilhamos desse ponto de vista, já que ele deixou de ser totalmente válido e no futuro próximo deixará de sê-lo por completo. Com efeito, a opinião pública ressente-se cada vez mais profundamente da alteração de seu quadro essencial, o perigo biológico em que as poluições a colocam. $O$ instinto de conservação entra em jogo: é mais forte que os xaropes políticos lenitivos. "Há coisas no ar" ainda nas regiões conformistas, como a Alsácia ou o país de Bade. Os tecnocratas se defrontam com um obstáculo que acreditaram ter neutralizado mediante o jogo combinado dos procedimentos administrativos e da informação truncada. Daqui a pouco, poder-se-á prever que a qualidade das águas e a poluição do ar, as doses da radiação e os dejetos térmicos serão objeto de medidas oficiais estabelecidas, como o PNB, e que haverá alguém que pretenderá dar explicações semelhantes àquelas de um engenheiro das minas oficiais de potassa da Alsácia. "Mas, afinal de contas, o cloreto de sódio não pode poluir, pois é solúvel".

Portanto, o estudo do meio encontrar-se-á dentro em breve numa situação 
semelhante à das questões socioeconômicas: ser-lhe-á necessário questionar o sistema oficial de coleta e tratamento dos dados.

A dialética baseada no trabalho de campo é, portanto, um elemento indispensável da percepção objetiva dos dados de base do raciocínio científico; quando ela está ausente, elaboram-se teorias que só têm relações longínquas com a realidade perceptível e que, por esse motivo, não têm qualquer utilidade social, pois não podem orientar a ação. A geomorfologia oferece o lamentável e destacado exemplo do "ciclo de erosão" e a "erosão normal" de W. M. Davis. Por acaso não recomendava o pontífice americano viras as costas à paisagem, "imaginá-la" antes de estudá-la e se limitar a constatar in loco que a realidade se parece realmente com esse produto de "imaginação criadora"? Será necessário lembrar o contexto em que foi elaborada essa aberração lógica? Será preciso sublinhar suas consequências nefastas e pôr-se em guarda contra as possíveis aplicações políticas dessa atitude? Alguns modelos da "nova geografia" foram estabelecidos, também, a partir de petições de princípio e respondem a uma necessidade bem definida. A oscilação dialética permanente entre o esquema, ou modelo, e os fatos permite evitar essas falácias. Dar a primazia aos fatos em vez de às ideias preconcebidas significa optar pela objetividade em relação ao idealismo e, portanto, denunciar-se como materialista.

\section{O campo na didática da geografia}

A dialética da pesquisa comporta uma oscilação permanente entre a formulação de conceitos e a análise dos dados, o estabelecimento de representações mentais, de esquemas explicativos e sua aplicação aos fatos estudados. A geografia nada mais é do que uma aplicação setorial desta abordagem geral. É por isso que consideramos pretensiosa e falsa, ao mesmo tempo, a atitude de atribuir-lhe uma tendência específica para a síntese ou a "globalidade". Todo pensamento racional tenta as sínteses, mais ou menos amplas de acordo com a experiência pessoal e as tendências dos autores, mas sempre parciais e incompletas. A abordagem sistêmica é adimensional e concilia o infinito temporal e espacial.

O objeto da pedagogia é ajudar os outros (não só os jovens) a utilizar essa dialética, a passar da análise dos dados à formulação de conceitos e às teorias explicativas, além de controlar e ajustar estas teorias ao melhor conhecimento dos fatos. É falso opor uma geografia "teórica" a outra, que seria a ciência do "concreto". Teoria e observação são indissociáveis numa abordagem dialética. Análise e síntese são os dois termos de uma oposição dialética, ambos indissociáveis. Dissociá-los ou pior ainda, opô-los, é condenarse à derrota: eis a ideia central a ser assimilada. A abordagem sistêmica nos mostra a falta de limites no tempo e no espaço. Com efeito, todos os sistemas naturais são sistemas abertos. Sob o ponto de vista demográfico, a Terra é um sistema fechado, já que não existe migração em direção a outros corpos celestes nem provenientes deles, mas sob o ponto de vista da Geografia Física ela é um sistema aberto que recebe energia do Sol e que reenvia uma parte dessa energia ao espaço. Quando estudo os paleoclimas quaternários, devo procurar elementos de explicação entre os astrônomos: variações de radiação solar, 
interceptação desta radiação pelas nuvens cósmicas etc. A abordagem sistêmica implica o desaparecimento das barreiras puramente artificiais que as tecnoestruturas colocam entre as disciplinas. $O$ melão não tem costelas para ser mais facilmente cortado em pedaços e comido em família, contrariamente à crença de Bernardin de Saint-Pierre! Os fatos que estudamos existem independentemente de nossas disciplinas e, geralmente, antes que elas se organizem... A abordagem sistêmica requer necessariamente um trabalho interdisciplinar. A formação inicial deve desenvolver a aptidão para esse trabalho. $O$ trabalho interdisciplinar requer uma metodologia comum e uma linguagem que permita a comunicação para que objetivos comuns possam ser atingidos. É necessário, portanto, insistir na metodologia, que para mim é a abordagem sistêmica. Essa formação metodológica ampla permite ainda tanto a formação permanente quanto a passagem de um objeto a outro. É o contrário da formação à prussiana, que visa à aquisição por parte do operário, de gestos automáticos ao longo da linha de montagem. Infelizmente, esse tipo de ensino é o que alguns gostariam de ver posto em prática no ensino técnico, IUT inclusive. Certamente, sob esse ponto de vista, o dono da máquina é também o dono do operário, despido de toda autonomia frente à máquina e ao processo de produção.

Mas essa formação metodológica, a meu ver, deve também ser dialética. $O$ método não pode ser ensinado como tal. É necessário perceber dados, fatos, objetos, e raciocinar a respeito deles. Na medida em que esta experiência dos fatos se alarga, pode-se estender cada vez mais o domínio do raciocínio, da formulação de conceitos, o campo das teorias. A mesma lógica de abordagem aplica-se à pesquisa fundamental, à pesquisa aplicada, à formação. Indo do geral ao particular, examinemos agora a maneira como essas concepções se aplicam em geografia, já que é necessário limitar nosso objetivo e nossas ambições somente a uma parte, a um setor do conhecimento. Um ponto preliminar no processo de formação é a aptidão para apreender os dados. Para o botânico ou o geólogo, é a aquisição de noções de sistemática que permitem identificar plantas e animais. Para o historiador, é o conhecimento dos fatos.

Uma particularidade da geografia, que a meu ver deriva da atitude idealista que ela adotou amplamente, é a fraqueza da taxonomia. Desde o século XVIII, Linneu havia estabelecido as bases de uma classificação dos seres vivos. Na França, foram necessários os trabalhos da RCP 77 para que se estabelecesse uma primeira classificação dos fatos geomorfológicos, e não estamos atrasados, longe disso, em relação a outros países do mundo! Lacoste estava com a razão ao sublinhar o caráter pouco claro da noção de região e as petições de princípio vidalianas nesse sentido. Estas petições de princípio são contemporâneas das de W.M. Davis e se inserem no mesmo contexto filosófico e político. Tal convergência não é obra do acaso: seu estudo devia atrair aos historiadores das ciências...

Emgeografia, éaverdade, defrontamo-nos comumadificuldade: agrande diversidade de indivíduos opõe-se à definição de tipos, ponto de partida para o estabelecimento de uma taxonomia. Estamos em presença de uma dialética tipo-indivíduo: quais os critérios a ser considerados para definir um tipo, face à grande diversidade dos indivíduos? É 
necessário conhecer muitos indivíduos antes de pretender estabelecer esses critérios para, logo a seguir, controlar novamente a aplicação desses critérios a muitos indivíduos, para ajustá-los. A legenda das cartas geomorfológicas da RCP 77 foi desenvolvida dessa maneira, na forma de um trabalho coletivo: cada objeto recebe um número de código (para evitar as polêmicas relativas ao vocabulário), é representado por um símbolo e é submetido a critérios de identificação. É a primeira vez que se procedeu dessa forma num ramo da geografia. Atualmente, se está revisando essa legenda para lhe introduzir melhorias decorrentes do trabalho realizado por aqueles que a empregam há dez anos. Esse é um exemplo da abordagem dialética de que somos partidários.

De qualquer forma, devemos esclarecer que a geografia não é a única disciplina que deve enfrentar essa dialética tipo-indivíduo. Os mesmos problemas se colocam para todas as ciências da vida e do homem. As únicas que não precisam resolver esse problema são as ciências da matéria. Portanto, não nos isolemos: unamos nossos esforços. Na atual conjuntura histórica, a geografia tem muito a ganhar com isso.

Portanto, no nível de formação de base, é necessário ao geógrafo:

(a) adquirir o mais rapidamente possível uma ampla experiência, que permita a conceituação de tipos, isto é, dominar a dialética tipo-indivíduo. Essa experiência só pode se adquirida de maneira válida no campo, quer se trate de identificar um relevo de costa, um lençol aluvial, um pousio social, uma savana terras de cultivo reunidas, um centro comercial ou um bairro industrial. Quem quiser aprender russo deve ser capaz de reconhecer as letras e dominar o alfabeto russo. Só depois disso poderá adquirir o vocabulário e abordar a sintaxe...

(b) saber estudar os objetos que lhe interessam nas representações que deles são feitas: cartas, fotos aéreas, imagens de sensores remotos. Mesmo assim, o confronto como o campo é rigorosamente necessário, por um lado, para identificar os objetos, e, por outro, para avaliar precisamente os tipos de informação que podem ser extraídos dessas representações. Por exemplo, uma carta topográfica com curvas de nível não representa as rupturas de declive. Uma carta geológica responde a uma óptica basicamente estratigráfica, e nós precisamos conhecer sobretudo a litologia. Que é que encontramos numa carta geomorfológica, numa carta de vegetação, num cadastro (relações entre as propriedades e a exploração, o problema fundamental a ser colocado...), numa carta de população? Que informações extrair de uma foto aérea, dos diversos canais das imagens Landsat? Para tudo isso é necessária a prática, assim como para utilizar uma língua estrangeira.

A didática devia comportar uma oscilação dialética entre o campo e os exercícios na sala de aula: estudo de documentos, exposições orais, discursos. É necessário apresentar o que será observado recolocando-o num conjunto, mostrando que esse objeto pode ser estudado a partir de diversos pontos de vista, correspondentes às vezes a disciplinas diferentes, mas reconhecendo que esses pontos de vista são parciais, incompletos. Após o campo, é necessário extrair conclusões, ampliar conhecimentos. Essa didática requer meios materiais (se pudéssemos dispor para cada estudante das mesmas verbas 
das escolas de engenharia, estaríamos bem) e, sobretudo, um esforço considerável dos professores, que devem se sentir à vontade no plano científico (o que supõe a prática constante da pesquisa) e participar de uma vida em comum com os alunos.

Nas etapas mais avançadas da formação, é necessário abordar sucessivamente:

(c) o tratamento dos dados, que prolonga o parágrafo acima. Por exemplo, aplicarse-ão questionários e serão organizados quadros estatísticos, procurar-se-ão correlações a partir dos resultados obtidos. Ao efetuar levantamentos de campo, será preparada a minuta correspondente (biogeografia, geomorfologia, solos, uso da terra etc.). Passarse-á dos levantamentos às estatísticas e às correlações. A pessoa que está se formando deve se sentir à vontade ao usar os métodos de tratamento de dados: apresentação oral ou escrita, representação gráfica, tratamento estatístico. Sublinhemos que esses diferentes métodos não são específicos da geografia, que todos eles concorrem para a valorização do trabalho realizado, sendo portanto úteis sob o ponto de vista profissional tanto ao futuro pesquisador quanto ao futuro professor. Portanto, sua prática não se limita a um setor restrito do mercado de trabalho; pelo contrário, ela possibilita escolhas profissionais bastante amplas e, ainda, eventuais mudanças de campo de trabalho. Esta seria a maneira honesta de se chegar a essa "mobilidade da mão de obra", pela qual suspiram nossos dirigentes atuais e que é necessária ao crescimento dos indivíduos se chegarmos a construir uma sociedade mais justa.

(d) o confronto de teorias e de fatos, a maneira como se elaboram os esquemas explicativos (modelismo), o ajuste desses esquemas aos fatos, em síntese, toda a dialética que acabamos de expor. É aqui que deve ser realizado o alargamento interdisciplinar. No decorrer da fase já de ser mostrado que outros se interessam pelos mesmos fatos que nós, e nesse momento terão sido apresentados seus conceitos e seu vocabulário. Tratase agora de mostrar que os métodos de pesquisa transbordam das disciplinas, que as teorias explicativas não podem ser limitadas ao ponto de vista setorial.

A melhor maneira de se fazer isto é adquirir os conhecimentos complementares em certas disciplinas vizinhas, escolhidas em função das necessidades profissionais, e de participar de seminários de pesquisas interdisciplinar não como espectador passivo, mas praticando a pesquisa. O campo desempenha nesse ponto um papel variável, de acordo com os assuntos, mas amiúde importante.

O esquema proposto não é utópico. Nós o experimentamos na medida em que o dinheiro cada dia mais curto o permitiu e ao submeter-nos à humilhação de uma regulamentação cada dia mais preocupada com insignificâncias. Um dos meus colegas lembrava a esse respeito o Baixo Império. Continuaremos, como ele, na trajetória acelerada para a decadência de um fim de sociedade? O problema não é geográfico, é político! 